\title{
PhotoPhage: A Virus-based Photothermal Therapeutic Agent
}

\author{
Arezoo Shahrivarkevishahi, ${ }^{a}$ Michael A. Luzuriaga, ${ }^{a}$ Fabian C. Herbert, ${ }^{\text {a }}$ Alisia C. Tumac, ${ }^{\text {a }}$ Olivia R. \\ Brohlin, ${ }^{a}$ Yalini H. Wijesundara, ${ }^{a}$ Candace Benjamin, ${ }^{a}$ Hamilton Lee, ${ }^{a}$ Perouza Parsamian, ${ }^{a}$ and Jere- \\ miah J. Gassensmith. ${ }^{\mathrm{a}, \mathrm{b},{ }^{*}}$ \\ ${ }^{a}$ Department of Chemistry and Biochemistry, ${ }^{b}$ Department of Biomedical Engineering, The University of \\ Texas at Dallas, 800 West Campbell Rd., Richardson, TX 75080, USA
}

gassensmith@utdallas.edu

\begin{abstract}
Virus like particles (VLPs) are non-infectious multifunctional nanocarriers with the pathogenic-like architecture of viruses. They can serve as a safe platform for precise functionalization and immunization, which provides benefits in a wide range of biomedical applications. In this work, we describe the development of novel immunophotothermal agent for combinatorial photothermal ablation and immunotherapy based on VLP of bacteriophage Q $\beta$. The design was based on covalent conjugation of 212 water soluble near-infrared absorbing croconium dyes to lysine residues located on the surface of $Q \beta$, which turned it to a powerful NIR-absorber with photothermal efficiencies exceeding that of gold nanostructures. This PhotoPhage system generates heat upon $808 \mathrm{~nm}$ NIR laser radiation and causes significant cellular cytotoxicity that prevents the progression of primary tumors in mice. It is found that PhotoPhage not only acts as a PTT agent that initiates anti-tumor immune response, but also simultaneously acts as an immunoadjuvant that promotes maturation of dendritic cells, triggers T lymphocyte cells (CD4+, $\mathrm{CD} 8+$ ) and reduces suppressive $T$ regulatory cells leading to effective suppression of primary tumors, reducing lung metastases, and increasing survival time.
\end{abstract}

\section{Introduction}

Photothermal therapy (PTT) has emerged as a localized, noninvasive, and highly specific cancer treatment strategy that takes advantage of the heat sensitivity of cells to induce cellular death in tumors. ${ }^{1-3}$ The cellular death and injury promote the formation of damage associated molecular patterns (DAMPs) that aid in generating a systemic immune response against tumor sites. ${ }^{4-6}$ Typically, to achieve an efficient thermal ablation in the tumor microenvironment (TME), heating over $50{ }^{\circ} \mathrm{C}$ is required. ${ }^{7}$ The induced inflammation kills cancer cells by impairing protein and DNA function in addition to turning "cold" immune-dysfunctional TMEs into "hot" immunological environments by stimulating the production and release of DAMPs that prime the formation of activated dendritic cells and promote the production of cancer killing CD8+ T-cells. ${ }^{8-9}$ However, there is accumulating evidence that not only the induced immunological response from thermal ablation is not strong enough on its own to inhibit tumor growth at distant sites, but the release of DAMPs followed by inflammation may actually promote development and progression of tumors by inducing propagation of local immunosuppressive regulatory $\mathrm{T}$ (Treg) cells and myeloid derived suppressor cells (MDSC). ${ }^{8}, 10-11$ Therefore, PTT requires further strengthening of the antitumor immune response in situ to polarize the immune system towards the tumor metastatic cells and simultaneously decrease the immunosuppressive effect of the TMEs.

Another important factor in PTT treatment is using efficient photoabsorbers, particularly those that absorb light in the near-infrared (NIR) region (700-1100 nm), where biological molecules like hemoglobin and melanin are the most transparent. ${ }^{12}$ Organic-based photoabsorbing molecules and inorganic nanomaterials are the most commonly employed preclinical photothermal agents (PTAs) that absorb light in NIR region and facilitate efficient heat production. ${ }^{13-14}$ The 
NIR region allows for deeper light penetration through skin and underlying tissue and photothermally active NIR organic molecules such as heptametine ${ }^{15-16}$ and phthalocyanine ${ }^{17-18}$ - systems that show high biocompatibility and biodegradability - is an ongoing area of research. Problematically, many of these dyes, including the clinically approved indocyanine green (ICG), degrade rapidly from a self-inflicted generation of reactive oxygen species (ROS), which necessitates repeated dosing for effective PTT treatment. ${ }^{19-20}$ One approach to overcome these issues is with the use of inorganic PTAs like gold nanostructures, ${ }^{21}$ carbon nanomaterials ${ }^{22}$ and iron oxide nanoparticles, ${ }^{23}$ which have shown strong absorption cross sections and high photothermal stability; however, metal-nanoparticles, particularly those made from gold, are generally not biodegradable and remain inside the body for long periods of time ${ }^{24}$ Finding a balance between high photothermal stability and pharmacokinetics is a key challenge in selecting suitable photothermal materials to simultaneously improve therapeutic effect of PTT and fulfill its clinical efficiency. Recently, croconium dyes have shown promise as they possess high NIR extinction coefficients, low fluorescence quantum yields, and high photostability making them promising candidates for photothermal therapy ${ }^{25}$ Indeed, recent work has shown they have photothermal efficiencies comparable or even surpassing gold nanostructures and ICG. ${ }^{26}$ However, their in vivo performance is restricted by poor aqueous solubility, self-aggregation, short circulation half time, quick diffusion from tumor tissue, and rapid clearance from the body. ${ }^{27-28}$ We wondered if it were possible to combine the superior photophysical properties of the croconium system with a biodegradable nanoparticle platform to produce a next-generation PTT agent that induces specific tumor killing and immune activation.

Virus like particles (VLPs), noninfectious self-assembled protein-based nanoparticles derived from the self-assembled coat proteins of viral capsids, are promising candidates for next generation bioorganic-based photothermal agents. VLPs are biocompatible, biodegradable, thermally stable, monodisperse, and show polyvalent chemical modifiability, which all provide unique opportunities to design bespoke compositions with programmed function. ${ }^{29-36}$ Their highly organized and symmetric nature and nanometer size $(20-200 \mathrm{~nm})$ allow them to be efficiently taken up by toll-like receptors (TLRs) on antigen presenting cells (APCs) as a pathogen-associated molecular patterns (PAMPs) and drained to local lymph nodes to interact with immune cells. These properties have made VLPs attractive in a broad range of systems for drug delivery, vaccination, gene therapy, and imaging with a significant impact on immunology, medicine, nanotechnology, and biology. ${ }^{37-48}$

In this work, we take advantage of the immunogenicity and site specific functionalizability to engineer a photothermal and immunogenic phage $Q \beta$ we call PhotoPhage. The formulation is an effective photo-immunotherapy system in a triple negative breast cancer tumor model in $\mathrm{BALB} / \mathrm{c}$ mice with complicating lung metastasis. Specifically, we show VLP Q $\beta$ (Figure 1A), a $30 \mathrm{~nm}$ icosahedral nanoparticle that can be expressed in high yields, possesses exceptional thermostability, and has multiple functional handles for bioconjugation, ${ }^{49-53}$ serves as a good PhotoPhage following functionalization with hundreds of croconium dyes. Not only can PhotoPhage sustain significant bulk photothermal heating in vitro and in vivo without denaturing, the nanoparticle formulations show a significant enhancement in photothermal performance over free dye and considerable improvements in solubility. Moreover, PhotoPhage partitions into cells better than free croconium dye and achieves significantly greater heating in vivo compared to equimolar concentrations of free dye. This contribution not only causes higher in vitro and in vivo thermal cytotoxicity but also substantially improves T-cell and dendritic cell activation over the well-known immunomodulatory features of VLP QB. ${ }^{11,54-56}$ 


\section{Result and Discussion:}

\section{Synthesis of PhotoPhage}
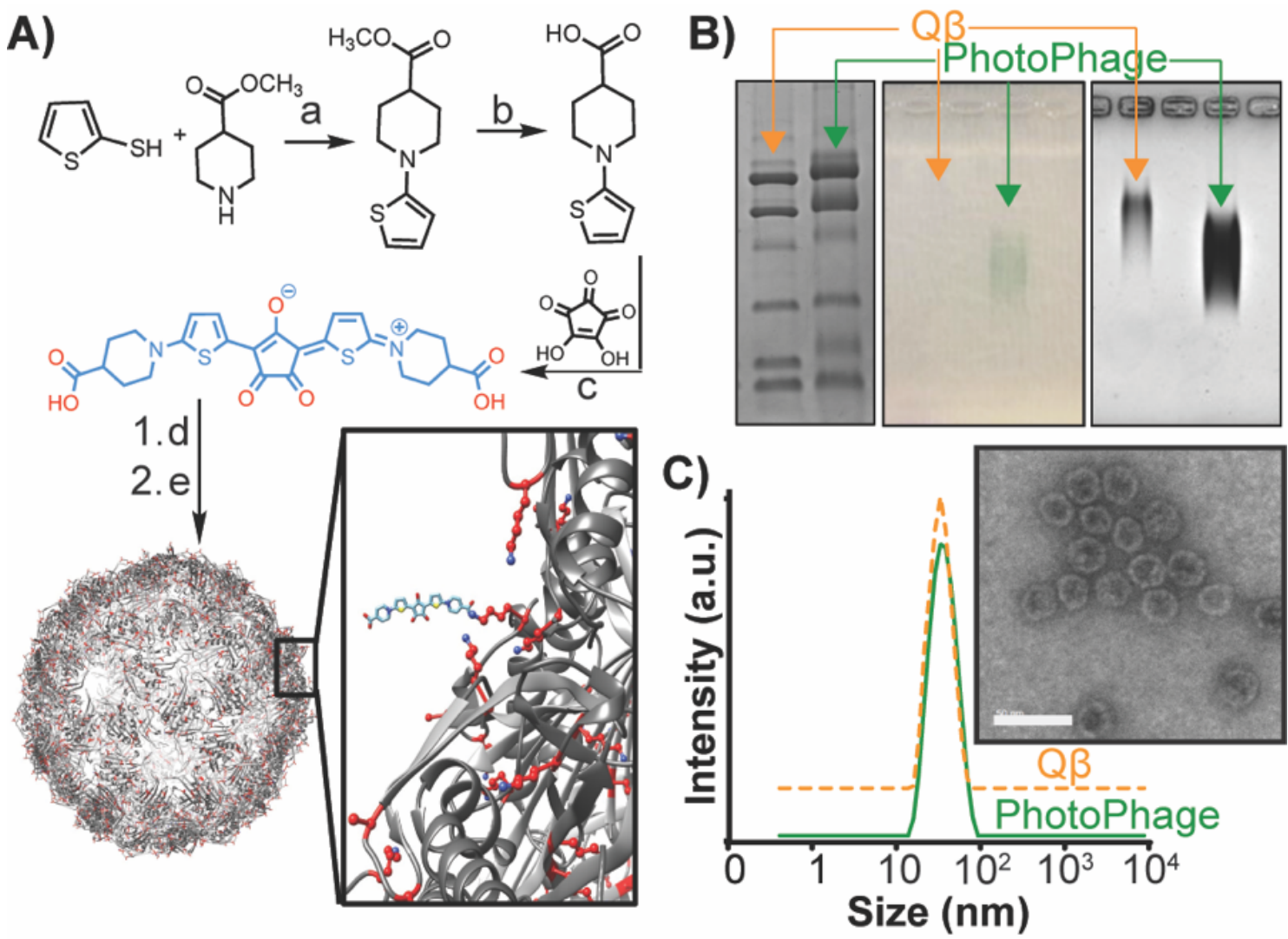

Figure 1. A) The overall synthetic bioconjugation strategy involves synthesis of the croconium dye by ${ }^{a}$ refluxing commercially available starting materials methyl isonipecotate and thiophene-2-thiol. ${ }^{\mathrm{b}}$ The resulting ester was deprotected under alkaline conditions and 'the final dye Croc (thiophene-croconaine dye) was produced in the condensation reaction between croconic acid. The free acids were dactivated as n-hydroxylsuccinimide (NHS) esters and eadded under dilute conditions to a solution of $Q \beta$ to prevent crosslinking. The functionalized $Q \beta$ was incubated briefly in water to hydrolyze the remaining NHS esters back to the free acid. B) Electrophoresis mobility analysis of $Q \beta$ before and after conjugation on SDS-PAGE (left) and agarose (center and right) gels show successful bioconjugation of dye to $Q \beta$. Non-reducing SDS-PAGE shows an increase in molecular weight of $Q \beta$ after bioconjugation. The unstained agarose (center) shows a green band in bright light in the same spot of Coomassiestained band (right) in agarose appears. The conjugate travels further toward the (+) electrode, which is anticipated from the replacement of lysines with carboxyl functions. C) DLS and TEM (insert) of $Q \beta$ and PhotoPhage demonstrate that the conjugation of croconium dye has no effect on size or polydispersity of the VLP.

As shown in Figure $1 \mathrm{~A}$, our approach for the covalent modification of bacteriophage $\mathrm{Q} \beta$ begins with the synthesis of a symmetric crocronium dye. Q $\beta$ VLP is composed of 180 identical capsid proteins, each with four reactive primary amine groups (three lysines and $\mathrm{N}$-terminus) exposed to the outer surface, presenting a total of 720 potential sites for Croc dye labeling. Bioconjugation was employed using N-hydroxysuccinimidyl (NHS) ester activated Croc (Croc-NHS) as a sitespecific and amine-reactive reagent. The resulting symmetric dye can potentially crosslink two VLPs, which produces aggregates that precipitate out of solution. To avoid this, the ratio and concentration of dye and $Q \beta$, incubation time, and purification procedures needed optimization. We found that 1:4 mole ratio of $\mathrm{Q} \beta$ to dye and $12 \mathrm{~h}$ incubation time produced the best colloidal stability, particle size, and dye loading for our final product, PhotoPhage. Denaturing polyacrylamide gel electrophoresis (Fig 2B left) shows an upward shift of the subunit bands of PhotoPhage, indicative of an increase in the molecular weight compared to $Q \beta$. Native agarose 
electrophoresis of the conjugate, which is visually seen as the blue band in the bright field image in Figure 1B center, shows greater migration toward the positive electrode compared to unfunctionalized $\mathrm{Q} \beta$ (Figure 1B, right), in line with the expected greater negative charge from the free carboxylates. Product morphology was confirmed by transmission electron microscopy (TEM) and dynamic light scattering (DLS) analysis (Figure $1 \mathrm{C}$ ) at $25^{\circ} \mathrm{C}$, which shows a nearly unchanged hydrodynamic radius from unfunctionalized $Q \beta(32.95 \pm 0.12 \mathrm{~nm})$ following attachment of the Croc dye $(33.10 \pm 0.15 \mathrm{~nm})$. The total number of dyes per capsid was determined to be approximately 1.2 by UV-Vis analyses, giving an average of 212 dyes per VLP.
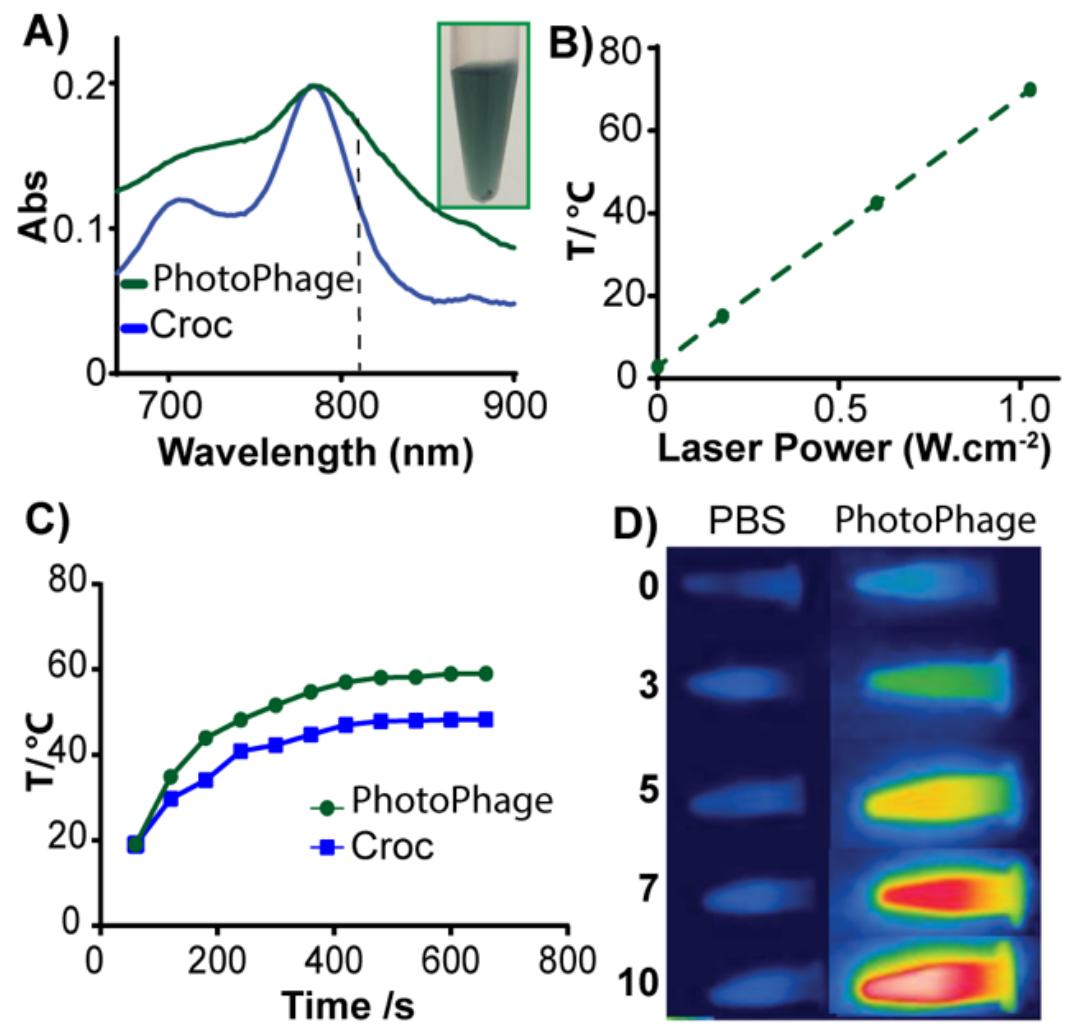

Figure 2. UV-Vis Spectrographic analyses of equal Molar concentration chromophores of Croc and PhotoPhage show A) a broadening of the NIR absorption of PhotoPhage (green line) compared to croconium dye (blue line). A photograph of PhotoPhage is shown in the insert. B) a linear relationship between PhotoPhage $(30 \mu \mathrm{g} / \mathrm{ml})$ solution temperature increases and laser power was observed after 3 min radiation (laser power was set 0.0015, 0.18, $\left.0.604,1.02 \mathrm{~W} \cdot \mathrm{cm}^{-2}\right)$. C) Photothermal heating profile of PhotoPhage and Croc at the same concentration $(30 \mu \mathrm{g} / \mathrm{ml})$ after $11 \mathrm{~min}$ laser irradiation $\left(808 \mathrm{~nm}, 0.18 \mathrm{~W} \cdot \mathrm{cm}^{-2}\right)$ shows a significant difference in temperature increase $\left(40.1^{\circ} \mathrm{C}\right.$ for PhotoPhage and $29.1^{\circ} \mathrm{C}$ for (roc). D) Temperature variations of PhotoPhage and PBS under laser irradiation are mapped and quantified by thermal camera. No obvious temperature increase was observed in PBS under the $808 \mathrm{~nm}$ laser irradiation $\left(0.18 \mathrm{~W} \cdot \mathrm{cm}^{-2}\right)$ at different radiation time.

\section{Spectral and photothermal analysis of Croc and PhotoPhage}

Dyes used in PTT function by absorbing laser light and converting this energy into heat through non-radiative (mostly vibrational) relaxation pathways. This is the most efficient when the dye is intensely colored and cannot dissipate energy through other relaxation pathways, e.g. fluorescence, electron transfer, or intersystem crossing. Croc is well suited for this as it has strong NIR absorption $\left(\lambda_{\max }=783 \mathrm{~nm}, \varepsilon_{\max }=2.0 \times 10^{5} \mathrm{~mol}^{-1} \mathrm{~cm}^{-1}\right.$ in water $),{ }^{57}$ negligible fluorescence, and low oxygen photosensitization - which also improves its photostability - a known issue with ICG and the extensively investigated heptamethine dyes. We were pleased to find that PhotoPhage exhibits a strong NIR absorption maximum $\left(\lambda_{\max } 783 \mathrm{~nm}\right)$ identical to that for free 
croconium dye yet the spectra is significantly broadened (Figure $1 \mathrm{~A}$ ). This broadening is pronounced in the NIR region, which helpfully promotes more efficient conversion of clinically used lasers (emissions centered at $808 \mathrm{~nm}$ ). This effect was made obvious when we compared the bulk solution photothermal response of PhotoPhage and free dye. Both solutions containing identical concentration of chromophore $(30 \mu \mathrm{g} / \mathrm{ml})$ were fitted with a thermocouple and placed in front of a thermal camera. Temperature change in each solution was monitored over $11 \mathrm{~min}$ of laser irradiation at $808 \mathrm{~nm}$ and $0.18 \mathrm{~W} \cdot \mathrm{cm}^{-2}$. As seen in Figure $2 \mathrm{C}$, the solutions showed marked difference in heating rates and maximum temperature with PhotoPhage showing a $\Delta T$ of $40.1^{\circ} \mathrm{C}$ and a $\mathrm{T}_{\max }$ of $59.1^{\circ} \mathrm{C}$ compared to free dye $\left(\Delta \mathrm{T}: 29.9^{\circ} \mathrm{C} \mathrm{T}_{\max }=48.5^{\circ} \mathrm{C}\right)$. Additional laser irradiation experiments have been done to fully investigate photothermal properties of PhotoPhage at different laser powers $\left(0.0015,0.18,0.604,1.02 \mathrm{~W} \cdot \mathrm{cm}^{-2}\right)$, times of radiation (1-10 $\mathrm{min}$ ) and various concentrations ( $0.1-1 \mathrm{mg} / \mathrm{ml}$ of Photophage). For instance, we found a linear increase in bulk temperature of solution that is linear with laser power. (Figure 2B, S3) Collectively, PhotoPhage appears to have superior photothermal properties compared to free dye, which allows for lower laser power density and dye concentration, potentially reducing side effects on normal tissue. To show that the $808 \mathrm{~nm}$ laser does not change the temperature of water itself, we irradiated a solution of buffer and PhotoPhage (Figure 2D, S3) and observed no temperature change in the PBS solution whereas we could heat a solution of PhotoPhage from room temperature to $61{ }^{\circ} \mathrm{C}$ with an $808 \mathrm{~nm}$ laser at $0.18 \mathrm{~W} \cdot \mathrm{cm}^{-2}$.
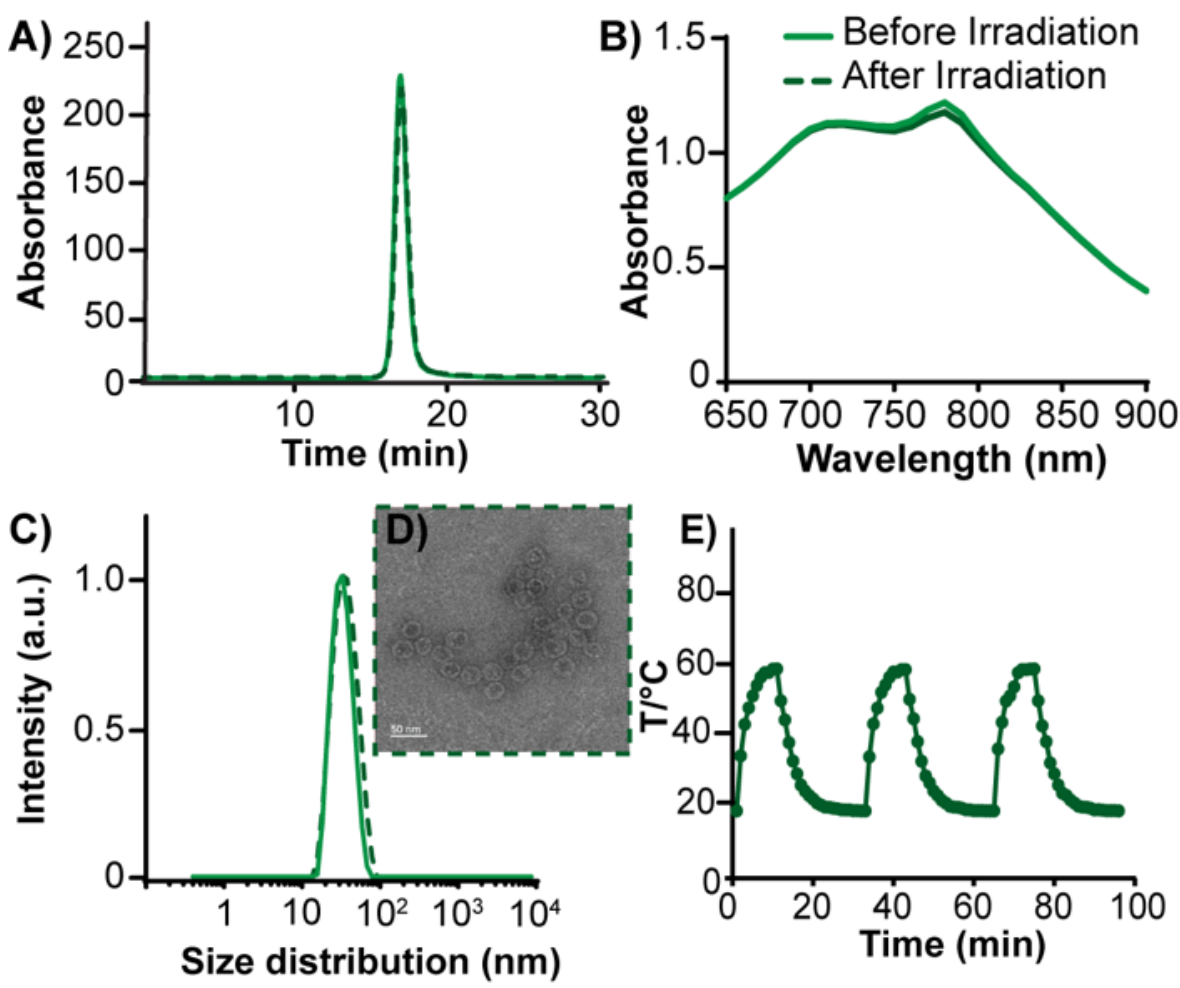

Figure 3. A) Photothermal stability of PhotoPhage after $10 \mathrm{~min}$ laser irradiation $\left(0.18 \mathrm{~W} \cdot \mathrm{cm}^{-2}\right)$ is shown by intact HPLC profile of PhotoPhage before and after radiation. B) No significant change in absorption spectra of PhotoPhage after laser induced heating for $10 \mathrm{~min}$. C) DLS and D) TEM data prove thermal stability of PhotoPhage in physiological environment with no morphology change after 10 min laser irradiation. E) Thermal cycling of PhotoPhage shows no change in heating profile after three cycles.

The photothermal stability of the PhotoPhage complex was proven by comparing size distribution, absorption, and size exclusion chromatography before and after $10 \mathrm{~min}$ of continuous laser irradiation $\left(0.18 \mathrm{~W} \cdot \mathrm{cm}^{-2}\right)$ as shown in Figure $3 \mathrm{~A}-\mathrm{D}$. The results showed no photobleaching, 
aggregation, or structural change, which clearly indicate high photostability of the system. To demonstrate the remarkable stability of PhotoPhage, we performed a thermal cycling experiment. A PhotoPhage solution ( $30 \mu \mathrm{g} / \mathrm{ml}$ of Croc concentration) was irradiated repeatedly ( 808 $\mathrm{nm}, 0.18 \mathrm{~W} \cdot \mathrm{cm}^{-2}$ ), and the temperature was monitored over the heating and cooling cycles, as shown in Figure 3E. PhotoPhage showed an impressive photothermal durability over at least 3 cycles with no obvious change in the maximum temperature. In line with strong absorbance in NIR region and high photostability, we further determined the photothermal efficiency of PhotoPhage as compared with existing photothermal materials - free Croc dye and gold nanorod (AuNR) -according to reported method. ${ }^{58}$ It was found Photophage has higher photothermal conversion efficiency $(77 \%)$ compared to Croc $(70 \%)$ and AuNR $(68 \%)$ which is in line with literature (Figure S4). From these results, we believe that the high photostability, durability, and remarkable photothermal conversion efficiency of PhotoPhage make it a good candidate for PTT. ${ }^{59}$

\section{Cellular uptake and in vitro PTT cytotoxicity}

Cellular uptake of both PhotoPhage and free Croc was assessed on 4T1 (murine breast cancer) cells. Because Croc lacks fluorescence, we determined uptake by measuring the amount of remaining dye in the supernatant after a $4 \mathrm{~h}$ incubation period. In a typical experiment, PhotoPhage and Croc were added to media in equal concentrations of chromophore. After $4 \mathrm{~h}$ the cells were removed, the media filtered, and the total absorption at the $\lambda_{\max }$ compared before and after. All concentrations were within the linear range of Beer's law, allowing direct calculation of before and after concentrations. As shown in Figure S5, cellular uptake of PhotoPhage is about twice that of croconium dye. Croc, being negatively charged, is very unlikely to partition into the cell, and so these results were not surprising. Next, the in vitro phototoxicity in 4T1 cells, ablation efficiency of PhotoPhage and Croc was determined by incubating identical concentrations (3.1 $\mu \mathrm{g} / \mathrm{ml}$ ) in cell culture. After $4 \mathrm{~h}$ incubation at $37^{\circ} \mathrm{C}$, cells were washed with PBS and fresh phenol red-free media to remove any remaining dye. Before laser irradiation, the microwell plate was equilibrated to $37^{\circ} \mathrm{C}$, as it has been shown in previous studies that initial temperature (RT vs 37 ${ }^{\circ} \mathrm{C}$ ) has significant effect in the in vitro PTT efficiency. All four experimental groups were exposed to an $808 \mathrm{~nm}$ laser for $10 \mathrm{~min}\left(0.18 \mathrm{~W} \cdot \mathrm{cm}^{-2}\right)$. The next day, cell viability in each well was determined by MTT assay. As shown in Figure S6, all formulations prior to laser radiation showed low toxicity whereas the cell viability of PhotoPhage dropped dramatically to $17 \%$ while free Croc dropped to only $65 \%$ after laser radiation. These results were further confirmed through visual analyses of cell viability via a dead cell assay. Cells were stained with red fluorescent dead-cell stain NucRed 647, incubated for 30 min, washed, and imaged by epifluorescence microscopy. (Figure S6). A strong red fluorescence for the PhotoPhage radiated group demonstrated the higher photothermal cytotoxicity compared to free Croc and PBS control groups.

\section{In vitro and in vivo photoimmunotheraputic efficacy of PhotoPhage}

In antitumor immunity, dendritic cells (DCs) are the most important and effective class of APCs and play a pivotal role in initiating and regulating innate and adaptive immunities. ${ }^{60}$ Generally, immature DCs ingest foreign materials through different surface receptors including pattern recognition receptors (PRRs) that trigger their maturation. ${ }^{61-62}$ PRRs detect PAMPs (derived from microorganisms) and DAMPs (produced by the body's dying cells). Mature DCs are capable of processing antigens into peptides for presenting on major histocompatibility complex class I/II (MHC-I/II) molecules that coincide with increased expression of B7-1/CD80 and B7-2/CD86 costimulatory molecules. Following maturation and antigen exposure, DCs migrate into the draining lymph node - where contact is mediated between DCs and T-cells - and promote the differentiation and proliferation of naïve T-cells into cytotoxic T lymphocytes (CTLs), which 
are key effector cells for anti-cancer immunity. ${ }^{9,63-65}$ Only mature DCs have the capability to elicit antitumor effector T-cell responses, which can be determined by assessing DC maturation in vitro following exposure to an antigen. It is well-known that non-genetic VLPs mimic viruses in terms of their size, structure, and antigenic epitopes. ${ }^{66-67}$ Their $20-200 \mathrm{~nm}$ size is in the optimal diameter range that can directly drain to the lymph node. In addition, because of their regular polyhedron structure and highly repetitive surface feature, VLPs are sensed as PAMPs by PRRs on the surface of DCs, which promote $\mathrm{DC}$ maturation for priming $\mathrm{CD} 4^{+} \mathrm{T}$ helper lymphocytes and $\mathrm{CD}^{+}$cytotoxic T lymphocytes. ${ }^{55}$ These cytotoxic T-cells can then fight systemic cancer at metastatic sites.

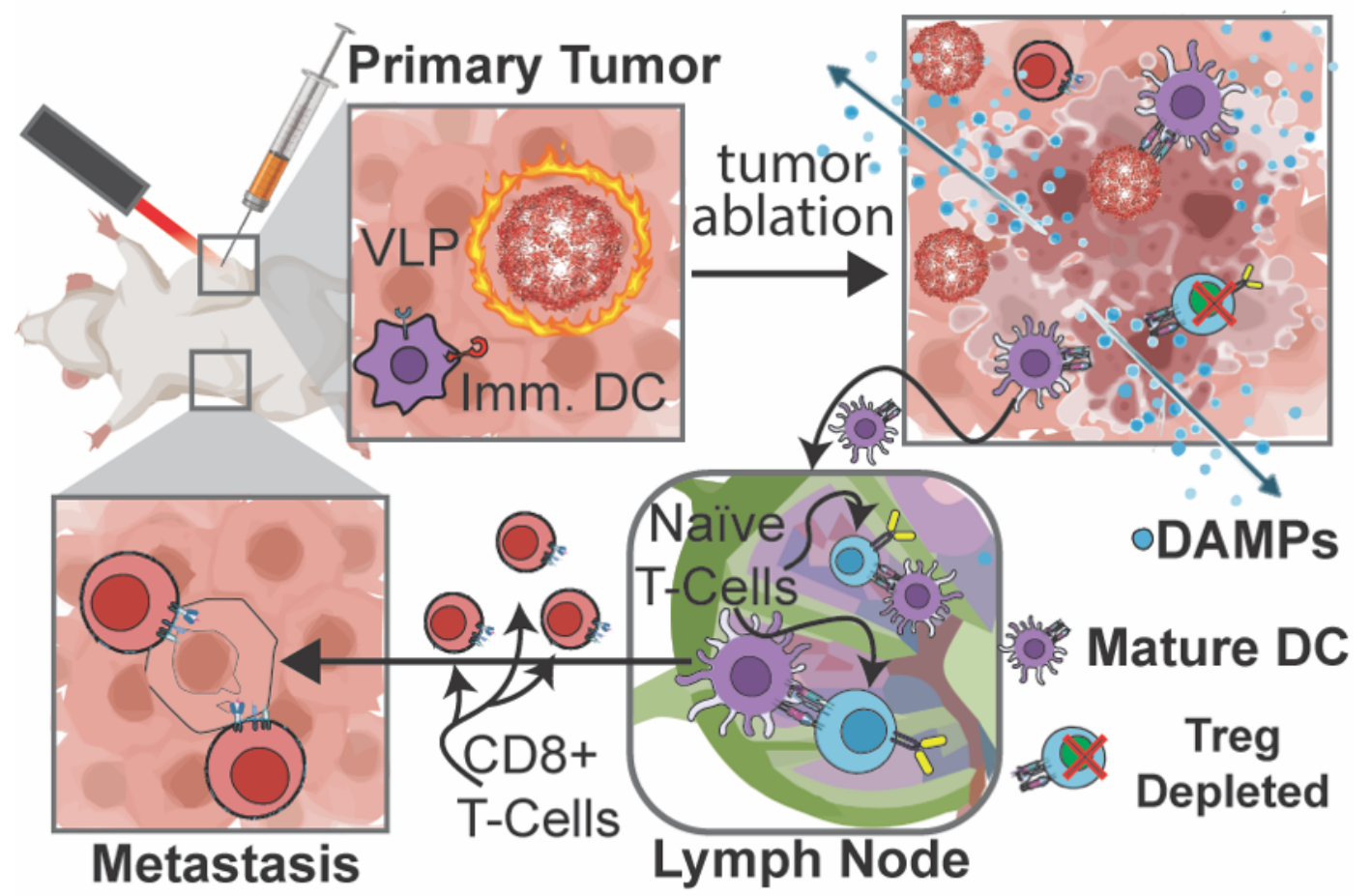

Scheme 1. Schematic illustration of PhotoPhage-initiated photothermally-triggered antitumor immune response. An initial photothermal excitation of the VLP causes an increase in temperature, which results in local tissue ablation. This causes local apotosis/necrosis and the release of immune stimulating DAMPs. The presence of intact VLP in the ablated tumor environment simulates a potential infection, which causes a down regulation of immunosuppressive response by suppressing Treg cell formation. These responses can be measured in the draining lymph node. In this lymph node, cancer antigens collected by activated dendritic cells can present to naïve T-cells, which mature to cytogenic CD8+ cells. These cells can then attack metastatic lesions.

We first investigated whether Q $\beta$ stimulates the maturation of DCs. To do that, the cultured bone marrow derived DCs (BMDCs) separated from BALB/c mice was incubated with different concentration of $Q \beta$ for $24 \mathrm{~h}$. The expression of DCs maturation markers - proteins called CD80 and CD86 - were determined by staining them with anti-CD80 and anti-CD86 fluorescent antibodies and quantified using flow cytometry (FCM). We found that $Q \beta$ could significantly upregulate the expression of CD86 \& CD80 and enhance the percentage of matured DCs $\left(\mathrm{CD} 11 \mathrm{c}^{+} \mathrm{CD} 80^{+} \mathrm{CD} 86^{+}\right)$in BMDCs at all concentrations tested compared to PBS (Figure S7). Next, we focused on evaluating the adaptive immunity triggered by $Q \beta$ at cellular levels after incubation with splenocytes harvested from a naïve mouse. Again, $Q \beta$ was able to promote the $\mathrm{CD} 4^{+} \mathrm{T}$ helper lymphocytes $\left(\mathrm{CD} 4^{+} \mathrm{CD} 3^{+} \mathrm{CD} 44^{+} \mathrm{CD} 62 \mathrm{~L}^{-}\right)$and $\mathrm{CD}^{+}$cytotoxic $\mathrm{T}$ lymphocytes $\left(\mathrm{CD} 8^{+} \mathrm{CD} 3^{+} \mathrm{CD} 44^{+} \mathrm{CD} 62 \mathrm{~L}^{-}\right)$which show possible immunoadjuvant potential of $\mathrm{Q} \beta$ in the PhotoPhage system to stimulate antitumor immune responses (Figure S7). These results encouraged us to investigate the in vivo antitumor immune response of PhotoPhage-based PTT 
compared to free Croc at equal dye concentrations. PTT induces apoptosis and necrosis, efficiently destroys tumor cells, subsequently releasing debris containing tumor-associated antigens and chemokines. ${ }^{68-69}$ These antigens are subsequently taken up by DCs and trafficked to the lymph node, triggering anti-tumor immune responses. Furthermore, DAMPs released from necrotic cancer cells such as heat shock proteins, calreticulin, and ATP can also promote DC maturation and assist in activating effector $\mathrm{CD} 8^{+} \mathrm{T}$ cells that enter to the systemic circulation to trigger the immunological responses for fighting against primary tumor and metastatic sites ${ }^{6}$, ${ }^{70}$ (Scheme 1). Our data shows that $\mathrm{Q} \beta$ can simultaneously act as an immunological agent to promote DC activation and enhance infiltration of CTLs. Thus, we expect PhotoPhage to exhibit a synergistic effect between photothermal therapy (Croc) and immunotherapy $(\mathrm{Q} \beta$ ) to enhance the antitumor immunity and tumor rejection.

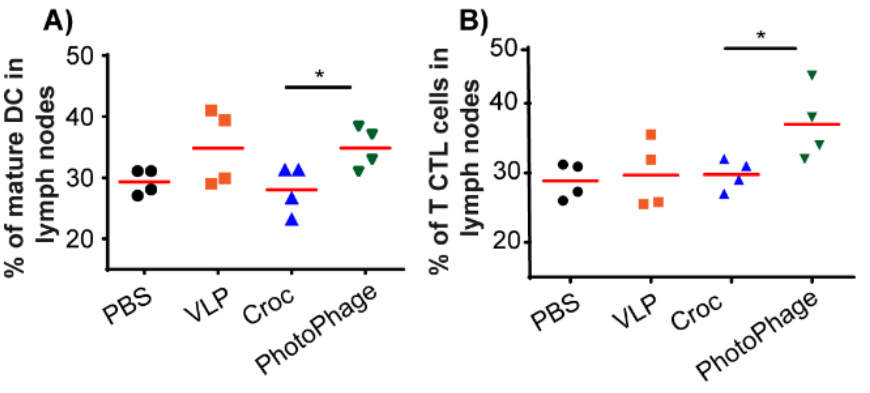

E)

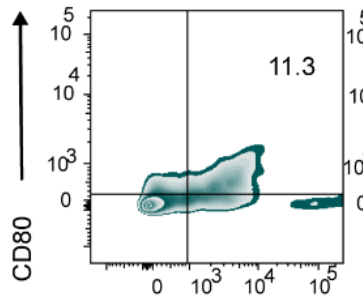

$$
\text { 6) }
$$

Croc

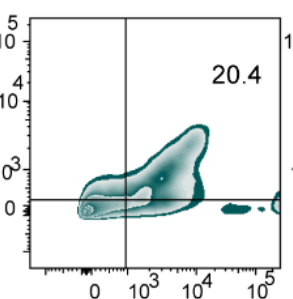

C)

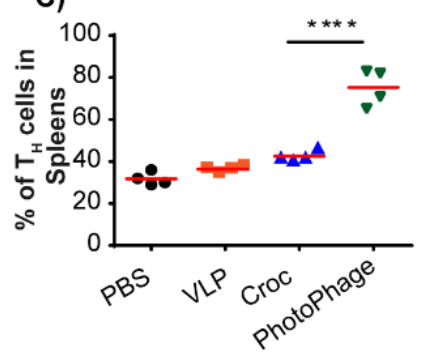

VLP
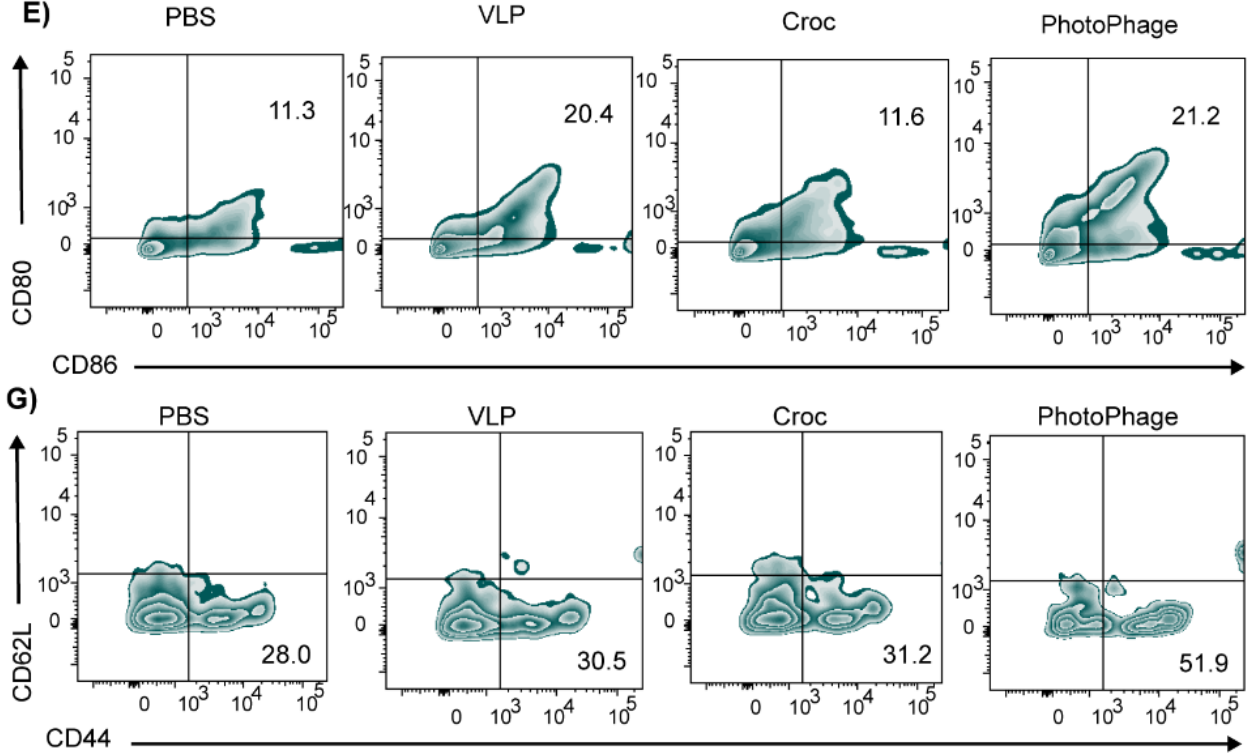

:
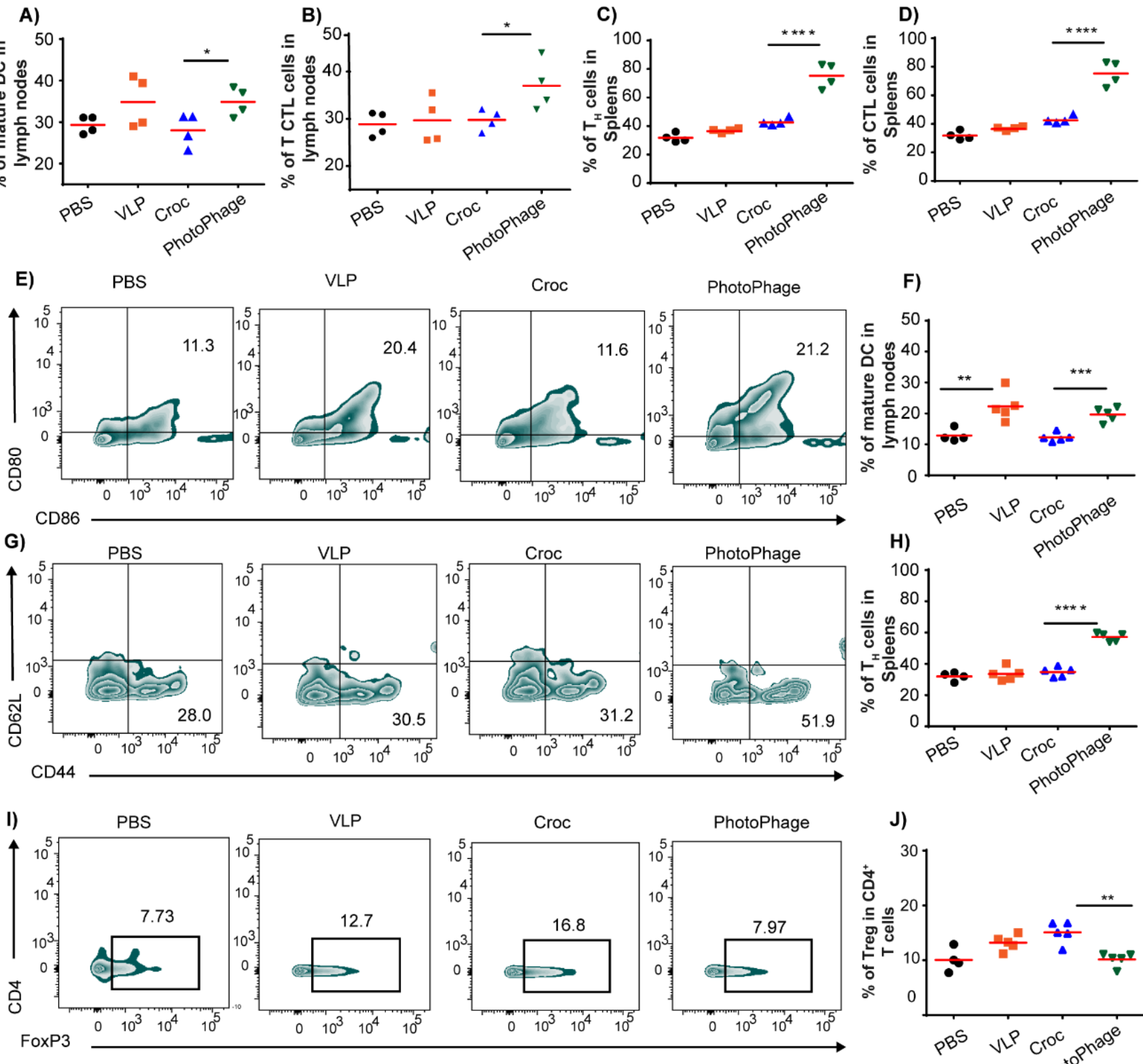

F)

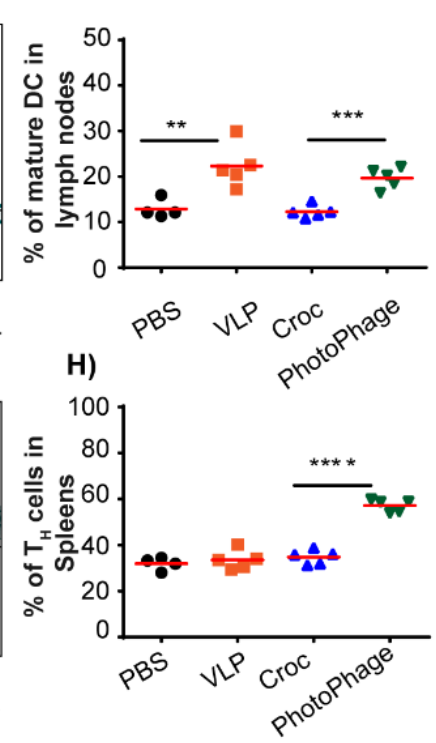

J)

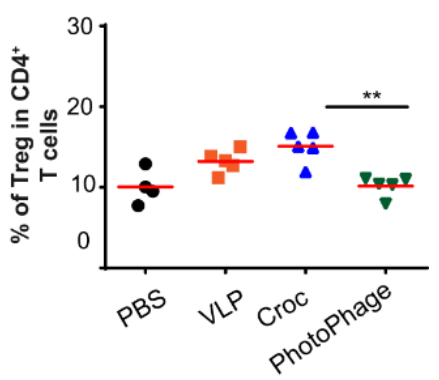

Figure 4. In vivo immune responses after the photothermal stimulation. A) DC maturation induced by various groups on mice bearing $4 \mathrm{~T} 1$ tumors (gated on CD11 $\mathrm{C}^{+} \mathrm{DC}$ cells) after PTT treatment $\left(\mathrm{T}_{\max }=54.2^{\circ} \mathrm{C}\right)$. Cells in the tumor draining lymph node were assessed by flow cytometry after staining for CD80, and CD86 expressions. B) Quantification of CTLs $\left(\mathrm{CD}^{+}\right)$in isolated lymph nodes. C-D) Percentage of helper T-cells $\left(\mathrm{CD} 4^{+}\right)$and CTLs in spleens. Single cell suspensions were processed from the spleen and analyzed by flow cytometry after anti-CD3, -CD4, -CD8, -CD44 and -CD62L staining. E-F) Representative flow cytometry plots showing expression of CD86 
and CD80 on DC of draining lymph node at different groups (gated on CD11 $\left.\mathrm{c}^{+}\right)$after PTT treatment $\left(\mathrm{T}_{\max }=44.0\right.$ $\left.{ }^{\circ} \mathrm{C}\right)$. G-H) Representative flow cytometry plots of effector $\mathrm{CD} 4^{+}$in spleen cells of different treatment groups analyzed by flow cytometry (stained with anti- CD3, -CD4, -CD44 and -CD62L). I-J) Representative flow cytometry plots showing percentages (gated on $\mathrm{CD}^{+}$cells) of $\mathrm{CD}^{+}{ }^{+} \mathrm{FoxP} 3^{+} \mathrm{T}$ cells in the spleen after various treatments.

As shown in Figure 2C, PhotoPhage and Croc both showed favorable photothermal effects in a wide temperature range $\left(40-60^{\circ} \mathrm{C}\right)$; thus, we set up our in vivo experiment to evaluate immunostimulatory activities of the combinational formulation compared to PTT alone. BALB/C mice $(n=20)$ were inoculated with 4T1 cells and grown until they had a primary tumor size of 100 $\mathrm{mm}^{3}$. The mice were separated into four groups $(\mathrm{n}=5)$ and injected with PBS, Q $\beta$, Croc, or PhotoPhage (same dye concentration as free Croc). Two hours post injection, they were irradiated with $808 \mathrm{~nm}$ laser for $10 \mathrm{~min}\left(0.18 \mathrm{~W} \cdot \mathrm{cm}^{-2}\right)$. Even though the amount of NIR dye was the same for Photophage and free Croc group, the temperature at the tumor surface was higher for PhotoPhage $\left(54 \pm 2^{\circ} \mathrm{C}\right)$ compared to free $\operatorname{Croc}\left(40 \pm 1^{\circ} \mathrm{C}\right)$, which can be ascribed to a more rapid clearance of free Croc from the tumor as well as greater photothermal efficiency of Photophage at $808 \mathrm{~nm}$. Three days post treatment, the mice were sacrificed, and the spleen and draining lymph node were collected to analyze the T lymphocytes and mature DCs by flow cytometry after co-staining with various markers. Interestingly, the percentage of matured DCs (CD11 ${ }^{+}$ $\mathrm{CD}^{\circ} 0^{+} \mathrm{CD}^{+} 6^{+}$) in the draining lymph node from PhotoPhage $24 \%$ greater than the Croc group, as shown by higher expression of costimulatory molecules CD80 and CD86 (Figure 4A), validating PhotoPhage's in vitro behavior, and showing it can enhance the activation of APCs better than each formulation alone. We also determined how PhotoPhage affects CD8 ${ }^{+} \mathrm{T}$ lymphocyte cells in the draining lymph node and found a significant number of activated (CD44 ${ }^{+} \mathrm{CD}^{-} \mathrm{L}^{-}$) $\mathrm{CD}^{+} \mathrm{T}$ cells in PhotoPhage group compared to other treated groups (Figure 4B).

We next identified whether PhotoPhage is able to stimulate a systemic immune response. The population of activated $\mathrm{CD}^{+}$cytotoxic T-cell $\left(\mathrm{CD} 8{ }^{+} \mathrm{CD} 44^{+} \mathrm{CD}^{+} \mathrm{L}^{-}\right)$and $\mathrm{CD}^{+}$effector $\mathrm{T}$-cell $\left(\mathrm{CD} 4^{+} \mathrm{CD} 44^{+} \mathrm{CD}^{-}\right)$were quantified in spleens by FCM after various treatments. Compared to either Croc or $\mathrm{Q} \beta$ alone, the combination treatment resulted in 2.10 fold increase in helper CD4 ${ }^{+}$ T-cell and 2.12 fold increase in CTL CD8 ${ }^{+}$T-cells compared to Croc. $(p<0.05)$. Collectively these results demonstrate clearly that PhotoPhage can act as a powerful photothermal agent along with immunological behavior that significantly induces in vivo anti-tumor immune response. Next, spleen single cell suspension of four different groups of mice were stained with antiCD11c, -CD4, -CD44 and -CD62L antibodies to measure how much effector memory T-cells were expressed after each treatment. As displayed in Figure 4G-H significant $\mathrm{CD} 4^{+} \mathrm{CD} 44^{+} \mathrm{CD} 62 \mathrm{~L}^{-}$cells appeared for mice treated with PhotoPhage.

A major issue for all forms of radiotherapy is that, following tissue damage, the tumor microenvironment can develop immunosuppressive cells, such as regulatory T-cells (Treg), myeloidderived suppressor cells (MDSCs), and tumor-associated macrophages, which creates an immunological "cold" tumor that restricts the therapeutic performance. ${ }^{8,71-72}$ Several studies have reported $^{8,11}$ that the efficiency of PTT inversely correlates with Treg cells, an immunosuppressive subset of $\mathrm{CD}^{+} \mathrm{T}$ cells characterized by the expression of factor forkhead box protein P3 (FoxP3). Necrotic cell death induced by PTT causes an inflammatory response that promotes expression of Treg immunosuppressive molecules as a protective measure since normally an injury in a person such as a burn should not initiate a strong full-body immune response. We expected that $Q \beta$ as an immunopotentiator would attract more APCs and amplify the immune response and its presence as a foreign viral protein might "trick" the immune system into believing that the injury contains pathogens, which would turn off the immunosuppressive response. Therefore, we assessed the presence of $\mathrm{CD}^{+}{ }^{+} \mathrm{FoxP} 3^{+}$after different treatments by flow 
cytometry to investigate what the ratio of the effector $\mathrm{CD} 4^{+} \mathrm{T}$-cells vs Treg in the spleen-an organ that serves as a systemic repository for the immune system. As expected - and shown in Figure 4I-J - PTT alone produces a high suppressive environment while PhotoPhage-a combination of PTT and the immunoadjuvanting agent $Q \beta$-decreased the percentage of Tregs $\left(\right.$ lower $\left.\mathrm{CD}^{+} \mathrm{FoxP}^{+}\right)$. This is significant because cancer therapeutic efficacy associated with tumor suppression and higher survival time correlates with lower Tregs and higher effector T-cells.

\section{In vivo antitumor effect of PhotoPhage}

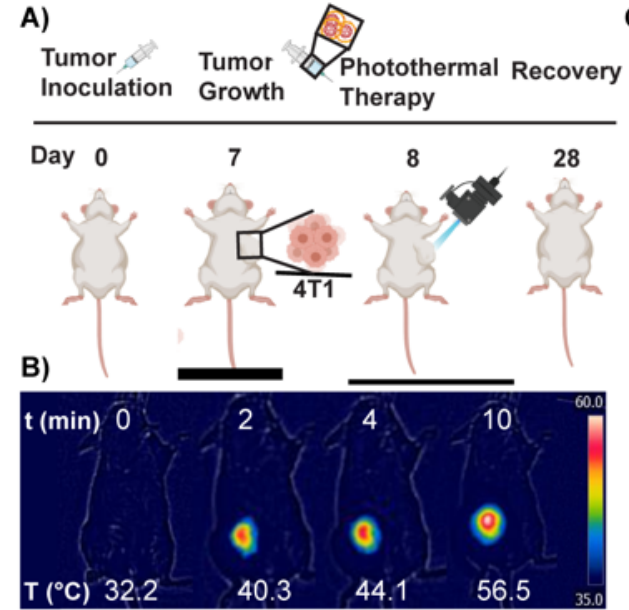

E)

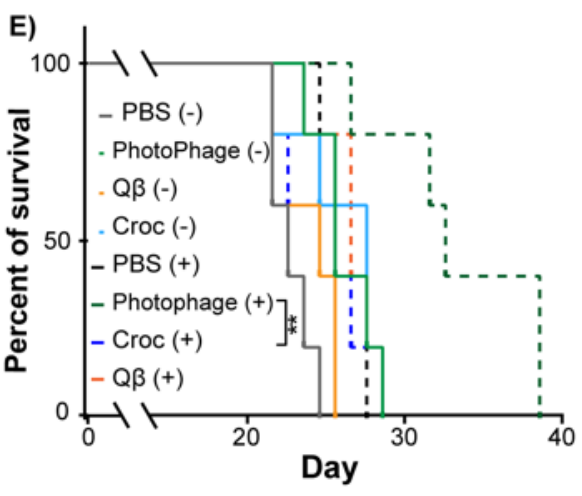

F)
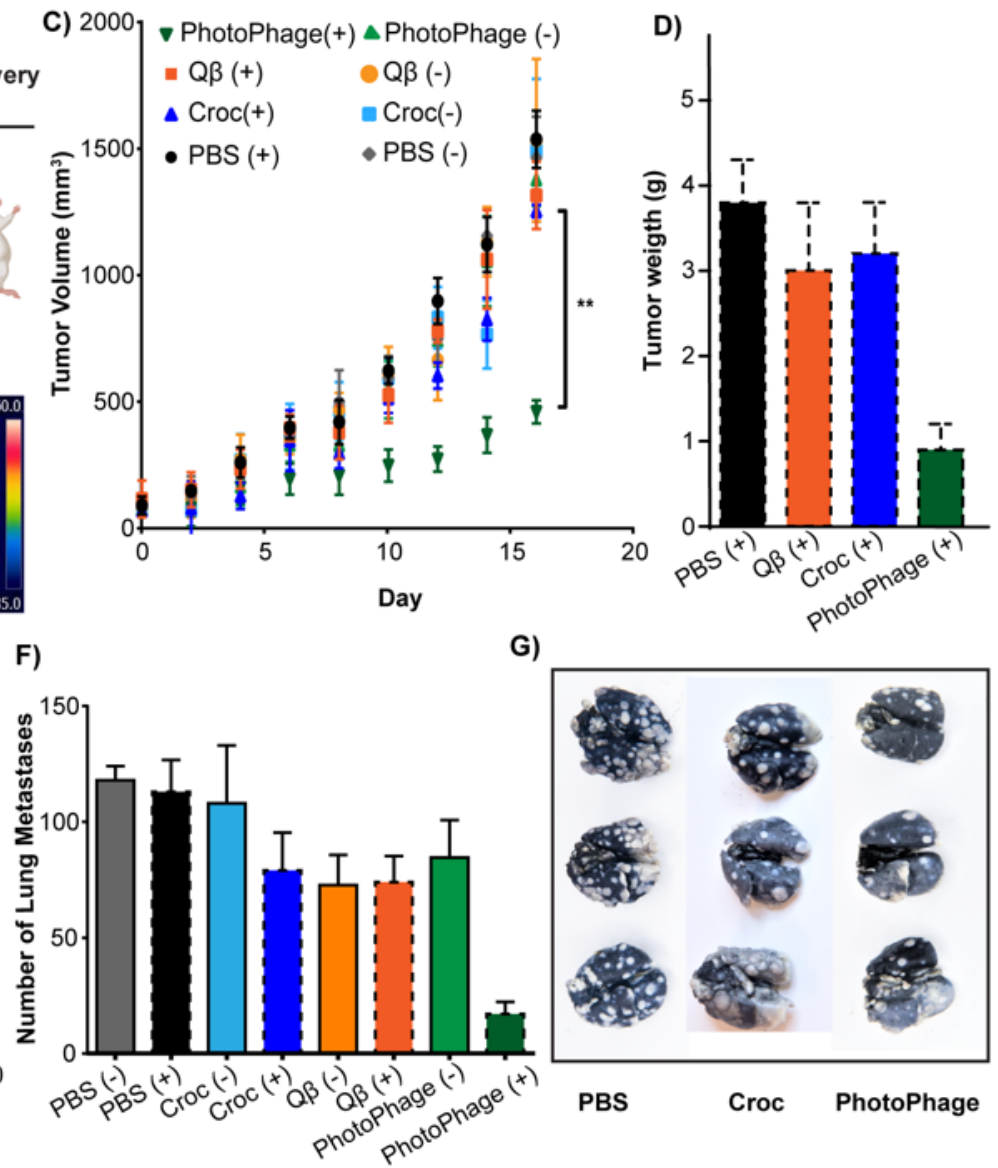

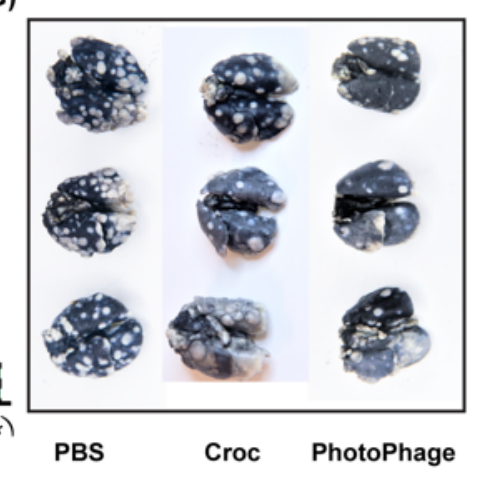

Figure 5. A) Experiment design of synergistic immunophotothermal therapy. B) Representative IR thermal images of tumor-bearing mice at different NIR radiation times $\left(808 \mathrm{~nm}, 0.18 \mathrm{~W} \cdot \mathrm{cm}^{-2}, 10 \mathrm{~min}\right)$ after intratumoral (i.t.) injection. C) Tumor growth curves of 4T1 tumor-bearing mice treated with PBS, Q $\beta$, Croc and PhotoPhage with and without laser radiation showing the most effective therapeutic approach is attributed to PhotoPhage, which exhibited the greatest restriction to tumor growth. D) Tumor weight as a representative of tumor suppression verified high antitumor performance of PhotoPhage compare to Croc, $Q \beta$, and PBS groups E) Survival study of $4 \mathrm{~T} 1$ tumor-bearing BALB/c mice $(n=5)$. F) Number of lung nodules after India ink staining. G) Representative images of India-inkinfused lungs of $\mathrm{Croc}$, PhotoPhage and PBS mice that white spot clearly demonstrate number of metastatic nodules per each group. ${ }^{* *} \mathrm{P}<0.05$.

Next, we assessed the anti-tumor effect of our system in the same murine mouse cancer model discussed above. 4T1 cells $\left(1 \times 10^{6}\right)$ were implanted into the abdominal mammary gland of 4-6 week old female BALB/c mice. Tumor development was allowed to proceed until the average tumor size reached to 5-6 $\mathrm{mm}$, after which mice were randomly divided into four groups with radiation and four groups without radiation for various treatment: PBS (negative control), Q $\beta$, and identical concentrations (by chromophore) of Croc and PhotoPhage. Following 
randomization, mice from each group $(n=5)$ were injected intratumorally ${ }^{73}$ and $2 \mathrm{~h}$ later, laser treatment was performed $\left(808 \mathrm{~nm}, 0.18 \mathrm{~W} \cdot \mathrm{cm}^{-2}, 10 \mathrm{~min}\right)$ as schematically shown in Figure 5A. The effect of treatment was evaluated by monitoring body weight of the mice and measuring tumor volume over the course of $16 \mathrm{~d}$. Tumor volumes were measured using calipers every other day after treatment and calculated according to the equation: $\mathrm{Vol}=$ (tumor length) $\times($ tumor width $) \cdot 2 / 2$. The tumors treated with PhotoPhage plus laser irradiation developed a large black scab on the tumor site and showed slower tumor growth compared all other experimental groups. The body weight of each groups was monitored over $16 \mathrm{~d}$ and we found no significant change, which suggests PhotoPhage, $Q \beta$, and croc did not induce toxicity (Figure S8). The irradiated Croc dye and $Q \beta$ by itself slightly delayed the growth of the primary tumor though nowhere near as much as the PhotoPhage formulation, which caused obvious tumor ablation after NIR laser exposure. The degree of tumor ablation and recission induced by different groups was further confirmed through tumor weight, as shown at Figure 5D, PhotoPhage again produced significant suppression on tumor growth compared to $Q \beta$ and Croc alone. Survival of the different groups of treated tumor-bearing mice was studied over 38 days following the initial tumor inoculation. As shown in the Kaplan-Meier survival curve, illustrated in Figure 5E, only PhotoPhage prolonged survival time compared to other groups. Metastatic burden was evaluated at day 16 post treatment by removing the lungs and staining them with India ink, which preferentially blackens healthy tissue making the metastasis stand out. Control groups (PBS) and unirradiated free Croc show statistically identical tumor burdens, as illustrated in Figure $5 \mathrm{~F}$ and $5 \mathrm{G}$. The unaltered $\mathrm{Q} \beta$ and irradiated free Croc groups all produced a modest and statistically significant decrease in metastatic burden, though none of these groups showed improved survival.

\section{Conclusion}

In this work we took advantage of VLP QB's biocompatibility, functionalizability, and modest immunogenicity to produce a new synthetic-biomaterial hybrid PTT "PhotoPhage." This formulation significantly improved the photophysical properties including photothermal conversion efficiency and water solubility as shown by an enhancement of cellular death upon $808 \mathrm{~nm}$ laser exposure compared to free dye. In addition, this synergistic combination showed excellent NIR light-induced tumor ablation by suppressing $70 \%$ of the primary breast cancer tumor in BALB/c mice bearing a highly metastatic $4 \mathrm{~T} 1$ tumor compared to $18 \%$ of Croc alone. PhotoPhage also prolonged survival time and reduced lung metastasis by $85 \%$ compared to control. An equimolar concentration of Croc managed to reduce metastatic tumor loading by $33 \%$. We expect this study to open up an exciting research direction for using VLP theragnostic platforms for precise and efficient cancer therapy.

\section{References}

1. Gao, D.; Guo, X.; Zhang, X.; Chen, S.; Wang, Y.; Chen, T.; Huang, G.; Gao, Y.; Tian, Z.; Yang, Z., Multifunctional phototheranostic nanomedicine for cancer imaging and treatment. Materials Today Bio 2020, 5, 100035.

2. Chen, F.; Cai, W., Nanomedicine for targeted photothermal cancer therapy: where are we now? Nanomedicine (Lond) 2015, 10 (1), 1-3.

3. Pinto, A.; Pocard, M., Photodynamic therapy and photothermal therapy for the treatment of peritoneal metastasis: a systematic review. Pleura Peritoneum 2018, 3 (4), 20180124-20180124.

4. $\quad K r y s k o$, D. V.; Agostinis, P.; Krysko, O.; Garg, A. D.; Bachert, C.; Lambrecht, B. N.; Vandenabeele, P., Emerging role of damage-associated molecular patterns derived from mitochondria in inflammation. Trends in immunology 2011, 32 (4), 157-64.

5. Chen, G. Y.; Nuñez, G., Sterile inflammation: sensing and reacting to damage. Nature reviews. Immunology 2010, 10 (12), 826-37.

6. Hernandez, C.; Huebener, P.; Schwabe, R. F., Damage-associated molecular patterns in cancer: a doubleedged sword. Oncogene 2016, 35 (46), 5931-5941. 
7. West, C. L.; Doughty, A. C. V.; Liu, K.; Chen, W. R., Monitoring tissue temperature during photothermal therapy for cancer. J BioX Res 2019, 2 (4), 159-168.

8. Li, L.; Yang, S.; Song, L.; Zeng, Y.; He, T.; Wang, N.; Yu, C.; Yin, T.; Liu, L.; Wei, X.; Wu, Q.; Wei, Y.; Yang, L.; Gong, C., An Endogenous Vaccine Based on Fluorophores and Multivalent Immunoadjuvants Regulates Tumor Micro-Environment for Synergistic Photothermal and Immunotherapy. Theranostics 2018, 8 (3), 860-873.

9. Wang, C.; Xu, L.; Liang, C.; Xiang, J.; Peng, R.; Liu, Z., Immunological responses triggered by photothermal therapy with carbon nanotubes in combination with anti-CTLA-4 therapy to inhibit cancer metastasis. Advanced materials (Deerfield Beach, Fla.) 2014, 26 (48), 8154-62.

10. Vakkila, J.; Lotze, M. T., Inflammation and necrosis promote tumour growth. Nature Reviews Immunology 2004, 4 (8), 641-648.

11. Bear, A. S.; Kennedy, L. C.; Young, J. K.; Perna, S. K.; Mattos Almeida, J. P.; Lin, A. Y.; Eckels, P. C.; Drezek, R. A.; Foster, A. E., Elimination of metastatic melanoma using gold nanoshell-enabled photothermal therapy and adoptive T cell transfer. PloS one 2013, 8 (7), e69073.

12. Wangzhong, S.; Sha, H.; William, J. S.; Adah, A., Review of the progress toward achieving heat confinement - the holy grail of photothermal therapy. Journal of Biomedical Optics 2017, 22 (8), 1-16.

13. Yang, Z.; Sun, Z.; Ren, Y.; Chen, X.; Zhang, W.; Zhu, X.; Mao, Z.; Shen, J.; Nie, S., Advances in nanomaterials for use in photothermal and photodynamic therapeutics (Review). Mol Med Rep 2019, 20 (1), 5-15. 14. Jaque, D.; Martínez Maestro, L.; del Rosal, B.; Haro-Gonzalez, P.; Benayas, A.; Plaza, J. L.; Martín Rodríguez, E.; García Solé, J., Nanoparticles for photothermal therapies. Nanoscale 2014, 6 (16), 9494-9530.

15. Lee, S.; George Thomas, R.; Ju Moon, M.; Ju Park, H.; Park, I.-K.; Lee, B.-I.; Yeon Jeong, Y., Near-Infrared Heptamethine Cyanine Based Iron Oxide Nanoparticles for Tumor Targeted Multimodal Imaging and Photothermal Therapy. Scientific Reports 2017, 7 (1), 2108.

16. Wu, F.; Lu, Y.; Mu, X.; Chen, Z.; Liu, S.; Zhou, X.; Liu, S.; Li, Z., Intriguing H-Aggregates of Heptamethine Cyanine for Imaging-Guided Photothermal Cancer Therapy. ACS applied materials \& interfaces 2020, 12 (29), 32388-32396.

17. Li, X.; Peng, X.-H.; Zheng, B.-D.; Tang, J.; Zhao, Y.; Zheng, B.-Y.; Ke, M.-R.; Huang, J.-D., New application of phthalocyanine molecules: from photodynamic therapy to photothermal therapy by means of structural regulation rather than formation of aggregates. Chemical Science 2018, 9 (8), 2098-2104.

18. Zheng, B.-D.; He, Q.-X.; Li, X.; Yoon, J.; Huang, J.-D., Phthalocyanines as contrast agents for photothermal therapy. Coordination Chemistry Reviews 2021, 426, 213548.

19. Cheung, C. C. L.; Ma, G.; Karatasos, K.; Seitsonen, J.; Ruokolainen, J.; Koffi, C.-R.; Hassan, H. A. F. M.; Al-Jamal, W. T., Liposome-Templated Indocyanine Green J- Aggregates for In Vivo Near-Infrared Imaging and Stable Photothermal Heating. Nanotheranostics 2020, 4 (2), 91-106.

20. Holzer, W.; Mauerer, M.; Penzkofer, A.; Szeimies, R. M.; Abels, C.; Landthaler, M.; Bäumler, W., Photostability and thermal stability of indocyanine green. Journal of Photochemistry and Photobiology B: Biology 1998, 47 (2), 155-164.

21. Vines, J. B.; Yoon, J.-H.; Ryu, N.-E.; Lim, D.-J.; Park, H., Gold Nanoparticles for Photothermal Cancer Therapy. Front Chem 2019, 7, 167-167.

22. Sobhani, Z.; Behnam, M. A.; Emami, F.; Dehghanian, A.; Jamhiri, I., Photothermal therapy of melanoma tumor using multiwalled carbon nanotubes. International journal of nanomedicine 2017, 12, 4509-4517.

23. Estelrich, J.; Busquets, M. A., Iron Oxide Nanoparticles in Photothermal Therapy. Molecules 2018, 23 (7), 1567.

24. Zhou, B.; Li, Y.; Niu, G.; Lan, M.; Jia, Q.; Liang, Q., Near-Infrared Organic Dye-Based Nanoagent for the Photothermal Therapy of Cancer. ACS applied materials \& interfaces 2016, 8 (44), 29899-29905.

25. Avirah, R. R.; Jyothish, K.; Ramaiah, D., Infrared Absorbing Croconaine Dyes: Synthesis and Metal lon Binding Properties. The Journal of Organic Chemistry 2008, 73 (1), 274-279.

26. Tang, L.; Zhang, F.; Yu, F.; Sun, W.; Song, M.; Chen, X.; Zhang, X.; Sun, X., Croconaine nanoparticles with enhanced tumor accumulation for multimodality cancer theranostics. Biomaterials 2017, 129, 28-36.

27. Harmatys, K. M.; Battles, P. M.; Peck, E. M.; Spence, G. T.; Roland, F. M.; Smith, B. D., Selective photothermal inactivation of cells labeled with near-infrared croconaine dye. Chemical Communications 2017, 53 (71), 9906-9909.

28. Spence, G. T.; Hartland, G. V.; Smith, B. D., Activated photothermal heating using croconaine dyes. Chemical Science 2013, 4 (11), 4240-4244.

29. Benjamin, C.; Brohlin, O.; Shahrivarkevishahi, A.; Gassensmith, J. J., Chapter 11 - Virus like particles: fundamental concepts, biological interactions, and clinical applications. In Nanoparticles for Biomedical Applications, Chung, E. J.; Leon, L.; Rinaldi, C., Eds. Elsevier: 2020; pp 153-174.

30. Herbert, F. C.; Brohlin, O. R.; Galbraith, T.; Benjamin, C.; Reyes, C. A.; Luzuriaga, M. A.; Shahrivarkevishahi, A.; Gassensmith, J. J., Supramolecular Encapsulation of Small-Ultrared Fluorescent Proteins in Virus-Like Nanoparticles for Noninvasive In Vivo Imaging Agents. Bioconjugate Chemistry 2020, 31 (5), 15291536. 
31. Wang, Q.; Lin, T.; Tang, L.; Johnson, J. E.; Finn, M. G., Icosahedral Virus Particles as Addressable Nanoscale Building Blocks. Angewandte Chemie International Edition 2002, 41 (3), 459-462.

32. Chung, Y. H.; Cai, H.; Steinmetz, N. F., Viral nanoparticles for drug delivery, imaging, immunotherapy, and theranostic applications. Advanced Drug Delivery Reviews 2020.

33. Park, J.; Chariou, P. L.; Steinmetz, N. F., Site-Specific Antibody Conjugation Strategy to Functionalize Virus-Based Nanoparticles. Bioconjugate Chemistry 2020, 31 (5), 1408-1416.

34. Aanei, I. L.; Francis, M. B., Dual Surface Modification of Genome-Free MS2 Capsids for Delivery Applications. Methods in molecular biology (Clifton, N.J.) 2018, 1776, 629-642.

35. Purwar, M.; Pokorski, J. K.; Singh, P.; Bhattacharyya, S.; Arendt, H.; DeStefano, J.; La Branche, C. C.; Montefiori, D. C.; Finn, M. G.; Varadarajan, R., Design, display and immunogenicity of HIV1 gp120 fragment immunogens on virus-like particles. Vaccine 2018, 36 (42), 6345-6353.

36. Benjamin, C. E.; Chen, Z.; Kang, P.; Wilson, B. A.; Li, N.; Nielsen, S. O.; Qin, Z.; Gassensmith, J. J., SiteSelective Nucleation and Size Control of Gold Nanoparticle Photothermal Antennae on the Pore Structures of a Virus. J Am Chem Soc 2018, 140 (49), 17226-17233.

37. Fiedler, J. D.; Fishman, M. R.; Brown, S. D.; Lau, J.; Finn, M. G., Multifunctional Enzyme Packaging and Catalysis in the Qß Protein Nanoparticle. Biomacromolecules 2018, 19 (10), 3945-3957.

38. Rampoldi, A.; Crooke, S. N.; Preininger, M. K.; Jha, R.; Maxwell, J.; Ding, L.; Spearman, P.; Finn, M. G.; $\mathrm{Xu}, \mathrm{C}$., Targeted Elimination of Tumorigenic Human Pluripotent Stem Cells Using Suicide-Inducing Virus-like Particles. ACS chemical biology 2018, 13 (8), 2329-2338.

39. Yin, Z.; Wu, X.; Kaczanowska, K.; Sungsuwan, S.; Comellas Aragones, M.; Pett, C.; Yu, J.; Baniel, C.; Westerlind, U.; Finn, M. G.; Huang, X., Antitumor Humoral and T Cell Responses by Mucin-1 Conjugates of Bacteriophage QB in Wild-type Mice. ACS chemical biology 2018, 13 (6), 1668-1676.

40. Shoeb, E.; Hefferon, K., Future of cancer immunotherapy using plant virus-based nanoparticles. Future Sci OA 2019, 5 (7), FSO401-FSO401.

41. Wang, C.; Fiering, S. N.; Steinmetz, N. F., Cowpea Mosaic Virus Promotes Anti-Tumor Activity and Immune Memory in a Mouse Ovarian Tumor Model. Advanced Therapeutics 2019, 2 (5), 1900003.

42. Pitek, A. S.; Hu, H.; Shukla, S.; Steinmetz, N. F., Cancer Theranostic Applications of Albumin-Coated Tobacco Mosaic Virus Nanoparticles. ACS applied materials \& interfaces 2018, 10 (46), 39468-39477.

43. Finbloom, J. A.; Han, K.; Aanei, I. L.; Hartman, E. C.; Finley, D. T.; Dedeo, M. T.; Fishman, M.; Downing, K. H.; Francis, M. B., Stable Disk Assemblies of a Tobacco Mosaic Virus Mutant as Nanoscale Scaffolds for Applications in Drug Delivery. Bioconjugate Chemistry 2016, 27 (10), 2480-2485.

44. Mohsen, M. O.; Speiser, D. E.; Knuth, A.; Bachmann, M. F., Virus-like particles for vaccination against cancer. WIREs Nanomedicine and Nanobiotechnology 2020, 12 (1), e1579.

45. Klimek, L.; Kündig, T.; Kramer, M. F.; Guethoff, S.; Jensen-Jarolim, E.; Schmidt-Weber, C. B.; Palomares, O.; Mohsen, M. O.; Jakob, T.; Bachmann, M., Virus-like particles (VLP) in prophylaxis and immunotherapy of allergic diseases. Allergo J Int 2018, 27 (8), 245-255.

46. Welch, R. P.; Lee, H.; Luzuriaga, M. A.; Brohlin, O. R.; Gassensmith, J. J., Protein-Polymer Delivery: Chemistry from the Cold Chain to the Clinic. Bioconjug Chem 2018, 29 (9), 2867-2883.

47. Lee, H.; Shahrivarkevishahi, A.; Lumata, J. L.; Luzuriaga, M. A.; Hagge, L. M.; Benjamin, C. E.; Brohlin, O. R.; Parish, C. R.; Firouzi, H. R.; Nielsen, S. O.; Lumata, L. L.; Gassensmith, J. J., Supramolecular and biomacromolecular enhancement of metal-free magnetic resonance imaging contrast agents. Chem Sci 2020, 11 (8), 2045-2050.

48. Dharmarwardana, M.; Martins, A. F.; Chen, Z.; Palacios, P. M.; Nowak, C. M.; Welch, R. P.; Li, S.; Luzuriaga, M. A.; Bleris, L.; Pierce, B. S.; Sherry, A. D.; Gassensmith, J. J., Nitroxyl Modified Tobacco Mosaic Virus as a Metal-Free High-Relaxivity MRI and EPR Active Superoxide Sensor. Mol Pharm 2018, 15 (8), 2973-2983.

49. Rohovie, M. J.; Nagasawa, M.; Swartz, J. R., Virus-like particles: Next-generation nanoparticles for targeted therapeutic delivery. Bioengineering \& Translational Medicine 2017, 2 (1), 43-57.

50. $\quad$ Chen, Z.; Boyd, S. D.; Calvo, J. S.; Murray, K. W.; Mejia, G. L.; Benjamin, C. E.; Welch, R. P.; Winkler, D. D.; Meloni, G.; D'Arcy, S.; Gassensmith, J. J., Fluorescent Functionalization across Quaternary Structure in a Viruslike Particle. Bioconjug Chem 2017, 28 (9), 2277-2283.

51. Chen, Z.; Detvo, S. T.; Pham, E.; Gassensmith, J. J., Making Conjugation-induced Fluorescent PEGylated Virus-like Particles by Dibromomaleimide-disulfide Chemistry. J Vis Exp 2018, (135).

52. Chen, Z.; Li, N.; Chen, L.; Lee, J.; Gassensmith, J. J., Dual Functionalized Bacteriophage Q $\beta$ as a Photocaged Drug Carrier. Small 2016, 12 (33), 4563-71.

53. Chen, Z.; Li, N.; Li, S.; Dharmarwardana, M.; Schlimme, A.; Gassensmith, J. J., Viral chemistry: the chemical functionalization of viral architectures to create new technology. Wiley Interdiscip Rev Nanomed Nanobiotechnol 2016, 8 (4), 512-34.

54. Mohsen, M. O.; Gomes, A. C.; Vogel, M.; Bachmann, M. F., Interaction of Viral Capsid-Derived Virus-Like Particles (VLPs) with the Innate Immune System. Vaccines (Basel) 2018, 6 (3), 37. 
55. Zepeda-Cervantes, J.; Ramírez-Jarquín, J. O.; Vaca, L., Interaction Between Virus-Like Particles (VLPs) and Pattern Recognition Receptors (PRRs) From Dendritic Cells (DCs): Toward Better Engineering of VLPs. Front Immunol 2020, 11, 1100-1100.

56. Qian, C.; Liu, X.; Xu, Q.; Wang, Z.; Chen, J.; Li, T.; Zheng, Q.; Yu, H.; Gu, Y.; Li, S.; Xia, N., Recent Progress on the Versatility of Virus-Like Particles. Vaccines (Basel) 2020, 8 (1).

57. Song, X.; Foley, J. W., A new water-soluble near-infrared croconium dye. Dyes and Pigments 2008, 78 (1), 60-64.

58. Liu, Y.; Ai, K.; Liu, J.; Deng, M.; He, Y.; Lu, L., Dopamine-Melanin Colloidal Nanospheres: An Efficient Near-Infrared Photothermal Therapeutic Agent for In Vivo Cancer Therapy. Advanced Materials 2013, 25 (9), 13531359.

59. $\quad K a n g$, P.; Chen, Z.; Nielsen, S. O.; Hoyt, K.; D'Arcy, S.; Gassensmith, J. J.; Qin, Z., Molecular Hyperthermia: Spatiotemporal Protein Unfolding and Inactivation by Nanosecond Plasmonic Heating. Small 2017, 13 (36).

60. Steinman, R. M., Linking innate to adaptive immunity through dendritic cells. Novartis Foundation symposium 2006, 279, 101-9; discussion 109-13, 216-9.

61. Wculek, S. K.; Cueto, F. J.; Mujal, A. M.; Melero, I.; Krummel, M. F.; Sancho, D., Dendritic cells in cancer immunology and immunotherapy. Nature Reviews Immunology 2020, 20 (1), 7-24.

62. Wang, J.; Chang, Y.; Luo, H.; Jiang, W.; Xu, L.; Chen, T.; Zhu, X., Designing immunogenic nanotherapeutics for photothermal-triggered immunotherapy involving reprogramming immunosuppression and activating systemic antitumor responses. Biomaterials 2020, 255, 120153.

63. Guo, Y.; Ran, Y.; Wang, Z.; Cheng, J.; Cao, Y.; Yang, C.; Liu, F.; Ran, H., Magnetic-responsive and targeted cancer nanotheranostics by PA/MR bimodal imaging-guided photothermally triggered immunotherapy. Biomaterials 2019, 219, 119370.

64. Mellman, I.; Coukos, G.; Dranoff, G., Cancer immunotherapy comes of age. Nature 2011, 480 (7378), 480489.

65. Janeway, C. A., Jr.; Bottomly, K., Signals and signs for lymphocyte responses. Cell 1994, 76 (2), 275-85.

66. Mohsen, M. O.; Gomes, A. C.; Vogel, M.; Bachmann, M. F., Interaction of Viral Capsid-Derived Virus-Like Particles (VLPs) with the Innate Immune System. Vaccines (Basel) 2018, 6 (3).

67. Grgacic, E. V. L.; Anderson, D. A., Virus-like particles: passport to immune recognition. Methods 2006, 40 (1), 60-65.

68. Kaczmarek, A.; Vandenabeele, P.; Krysko, Dmitri V., Necroptosis: The Release of Damage-Associated Molecular Patterns and Its Physiological Relevance. Immunity 2013, 38 (2), 209-223.

69. Xu, P.; Liang, F., Nanomaterial-Based Tumor Photothermal Immunotherapy. International journal of nanomedicine 2020, 15, 9159-9180.

70. Cheng, H.-W.; Tsao, H.-Y.; Chiang, C.-S.; Chen, S.-Y., Advances in Magnetic Nanoparticle-Mediated Cancer Immune-Theranostics. Advanced Healthcare Materials 2021, 10 (1), 2001451.

71. Li, C.; Jiang, P.; Wei, S.; Xu, X.; Wang, J., Regulatory T cells in tumor microenvironment: new mechanisms, potential therapeutic strategies and future prospects. Molecular Cancer 2020, 19 (1), 116.

72. Tormoen, G. W.; Crittenden, M. R.; Gough, M. J., Role of the immunosuppressive microenvironment in immunotherapy. Adv Radiat Oncol 2018, 3 (4), 520-526.

73. Marabelle, A.; Andtbacka, R.; Harrington, K.; Melero, I.; Leidner, R.; de Baere, T.; Robert, C.; Ascierto, P. A.; Baurain, J. F.; Imperiale, M.; Rahimian, S.; Tersago, D.; Klumper, E.; Hendriks, M.; Kumar, R.; Stern, M.; Öhrling, K.; Massacesi, C.; Tchakov, I.; Tse, A.; Douillard, J. Y.; Tabernero, J.; Haanen, J.; Brody, J., Starting the fight in the tumor: expert recommendations for the development of human intratumoral immunotherapy (HIT-IT). Ann Oncol 2018, 29 (11), 2163-2174. 